TITLE:

\title{
Tsunami Risk in Japanese Coast and Recent Mitigation Technique using Removable Breakwater
}

\author{
$\operatorname{AUTHOR}(\mathrm{S})$ :
}

Hiraishi, Tetsuya

\section{CITATION:}

Hiraishi, Tetsuya. Tsunami Risk in Japanese Coast and Recent Mitigation Technique using Removable Breakwater. International Journal of Ocean and Coastal Engineering 2019, 2(03n04): 1940002.

\section{ISSUE DATE:}

2019

URL:

http://hdl.handle.net/2433/255611

\section{RIGHT:}

Electronic version of an article published as International Journal of Ocean and Coastal Engineering, Vol. 02, No. 03n04, 1940002 (2019) https://doi.org/10.1142/S2529807019400025 @ 2019 World Scientific Publishing Company:; This is not the published version. Please cite only the published version.; この論文は出版社版でありません。引用の際には出版社 版をご確認ご利用ください。 


\title{
Tsunami Risk in Japanese Coast and Recent Mitigation Technique using Removable Breakwater
}

\author{
Tetsuya HIRAISHI \\ Disaster Prevention Research Institute, Kyoto University \\ Ujikawa Open Laboratory \\ Shimomisu, Yoko-oji, Fushimiku, Kyoto, 612-8235, Japan \\ Tel 81-75-611-0520, Fax 81-75-611-0530 \\ Hiraishi.tetsuya.2c@kyoto-u.ac.jp
}

\begin{abstract}
In this paper, the tsunami risk in the west coast of Japan is introduced. Especially the inundation risk in Osaka city is discussed. Three visor gate are installed at the mouths of main rivers in the city. The gates are mainly installed to prevent the storm surge due to typhoons but they are effective to reduce the tsunami height at the mouth point of river. Though the gates are necessary to prevent the tsunami inundation, the stability against tsunami forces is not enough because the gates were constructed in 1960s. Therefore the removable breakwater are now under consideration to reduce the tsunami force. The hydraulic experiment was carried out in order to investigate the applicability of the removable breakwater. The reduction rate by the breakwater was derived from the experiment.
\end{abstract}

Key words: hydraulic experiment, tsunami generation, removable breakwater, visor gate, tsunami height reduction rate

\section{Introduction}

Both of Japan and Taiwan are located on the Pacific-rim, so we have a high risk of strong earthquakes. Huge tsunami may be generated when the epicenter is located in offshore and the magnitude is enough large. The 2011 East Japan Great Earthquake was a remarkable example of such tsunami caused by maritime huge earthquake fault. Even in the west Japan, the huge tsunamis were generated periodically in our history. The epicenters of such tsunamiearthquakes are located in the south offshore of Shikoku Island or Kii Peninsula. That area is called "Nankai-do", so the tsunami generated with the earthquake-epicenter in such sea area is called Nankai-do Earthquake Tsunami. Figure 1 shows the recent earthquake map of Japan and the expected area where the Nankai-do Earthquake may happen. The history of the Nankaido-Earthquake Tsunami starts from A.C.658. Figure 2 shows the time history of the Nankaido-Earthquake Tsunami. The tsunami is generated periodically every 100 to 200 years. The magnitude of the earthquake is very strong and it is more than 8.0 except a few cases. The latest tsunami called "Showa Nankai Tsunami” was generated in 1946 so 63 years has passed since the last tsunami happened. The probability of occurrence of the next Nankai Earthquake is increasing year by year. The mitigation tools against tsunami attack should be urgently implemented especially in the metropolitan area bordering to the coast.

One of the important hardware mitigation tools is river gate controlling the storm surge. It is also applicable to tsunami prevention tool because the water level in storm surge is much

\footnotetext{
* This work was financially supported by the National Nature Science Foundation of China (Grant No. 50679076) Corresponding author. E-mail: gasemi@sut.ac.ir
} 
higher than in the tsunami. Innermost part of the target bay storm surge level becomes higher than tsunami level. The river gate-type is visor gate indicated in Figure 3. The height and width (span) is 20 and 50m respectively. The arch-type shown in Fig.3 is called "Visor Gate ". The gate is closed like Figure 4 in storm surge events.

On September 4, 2018, the target area (Osaka bay) was hit by a strong typhoon No.21. With the approach of the typhoon, the Kansai-Airport was heavily inundated and closed for 3 days. But no inundation happens at the innermost city area because of the gate protection. Figure 4 shows a photograph indicating the storm surge was prevented by the visor gate. Therefore the perfect maintenance of the Visor gate is necessary to keep the ability of the gate. However it is revealed that the gate was not safe against the first tsunami wave by structure balance calculation. Any barrier system become needed in front of the gate to reduce the tsunami pressure. We propose a removable breakwater to reduce tsunami pressures acting on the visor gate. This paper discussed the applicability of removable breakwater to reduce the tsunami wave pressure in front of the visor gate.

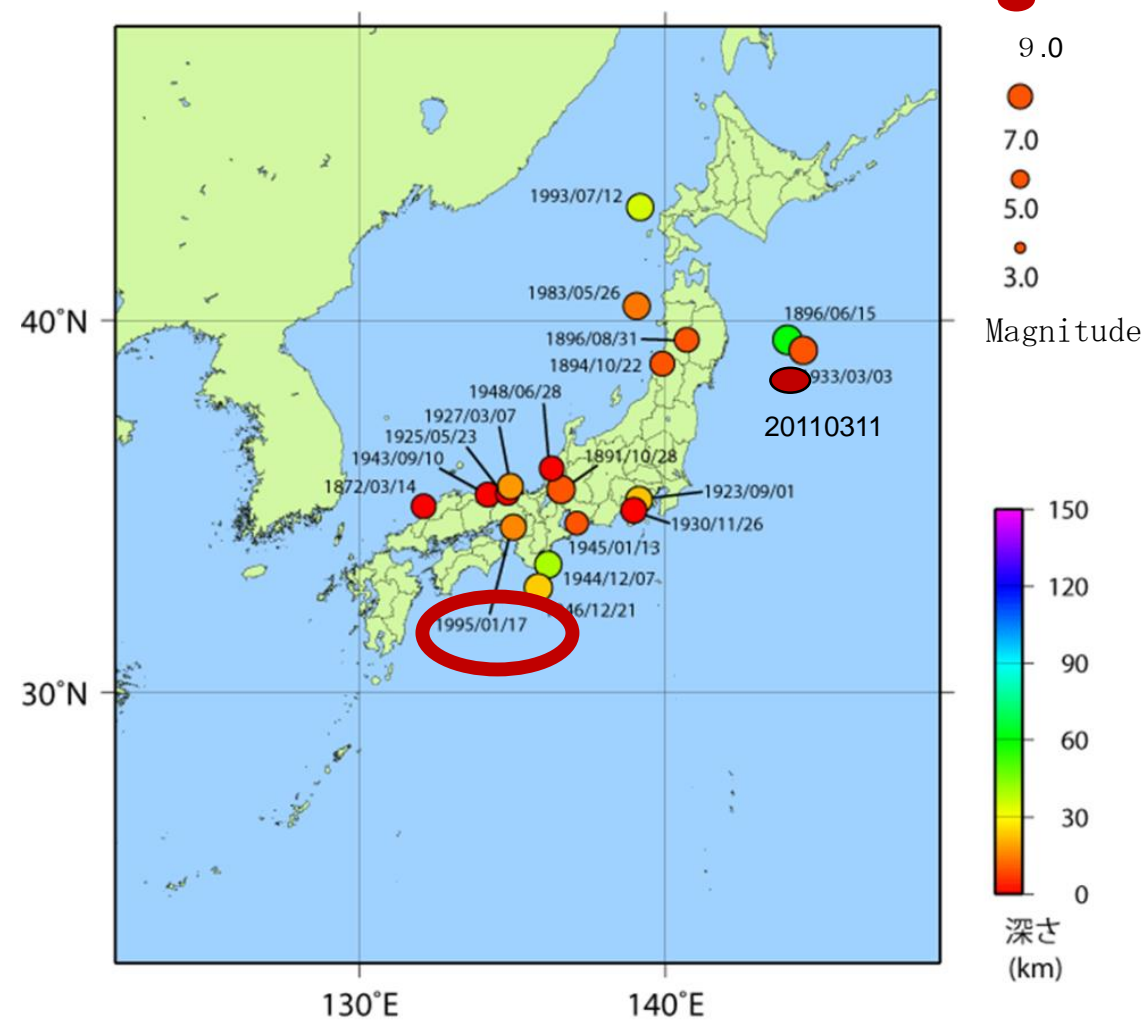

Fig.1 Area of Nankaido-Earthquake 


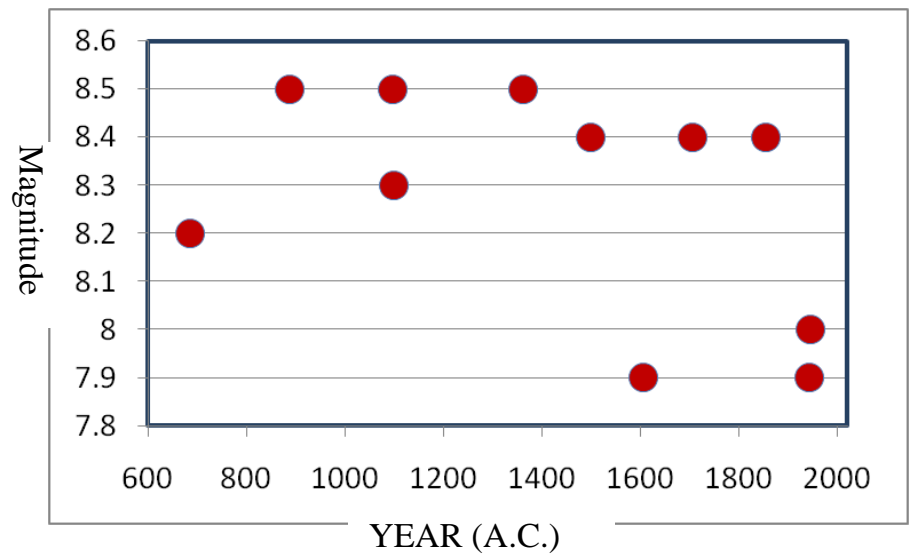

Fig. 2 Histry of Nankaido Earthquake

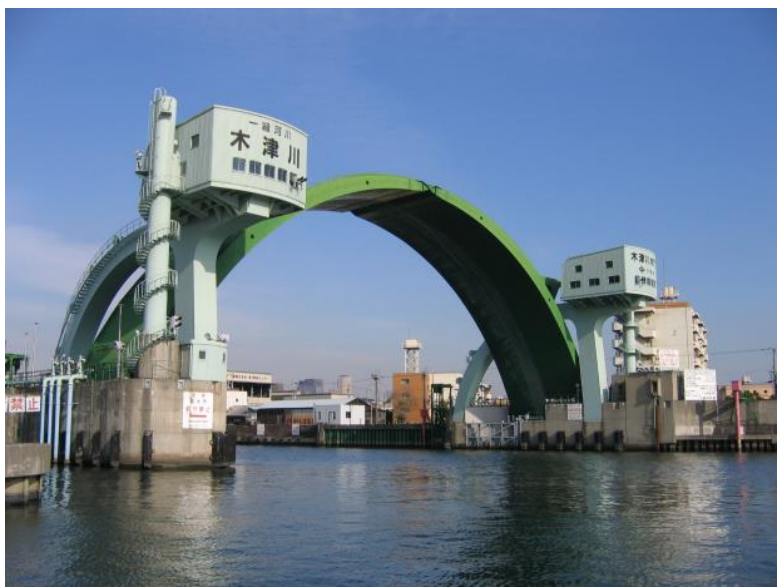

Fig.3 Visor gate in a river mouth ( presented by Osaka Prefecture)

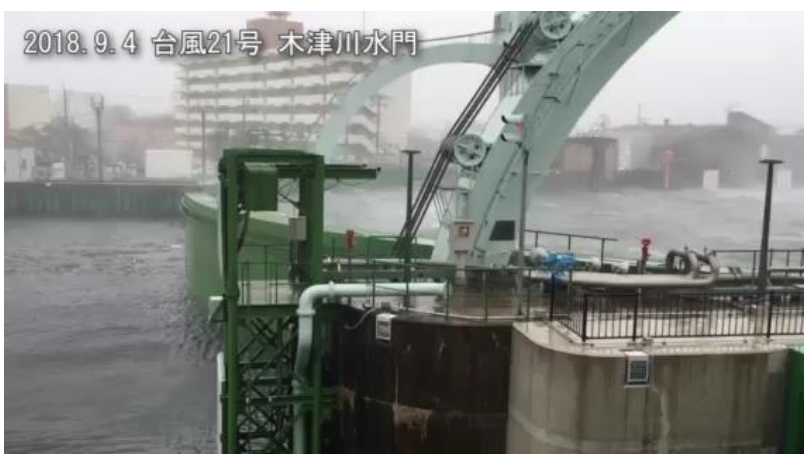

Fig.4 Prevention of Storm Surge on September 4, 2018 ( presented by Osaka Prefecture)

\footnotetext{
* This work was financially supported by the National Nature Science Foundation of China (Grant No. 50679076) Corresponding author. E-mail: gasemi@sut.ac.ir
} 


\section{Experimental Contents for Removable Breakwater}

Figure 5 shows the image of the Hydro-Plane type removable breakwater. The fundamental mechanism was tested and applicability was demonstrated by Azuma et al. ${ }^{1) 2(3), 3)}$ The breakwater consists of a base plate, a flouter and tension-tied rubbers. The flat float connected in rubber belts is capable to stand in the positive wave coming and also it stands up in negative waves. Standing by the negative waves becomes the prevention of dispersion of debris due to tsunami. The input tsunami wave is shown in Figure 6. A calculation done in the Osaka city government has concerned stability of the old gate and it concludes that the old visor gate would be collapsed due to tsunami forces. The gate crown height is enough high to reduce inundation area due to tsunami waves, therefore, the reduction of tsunami force is necessary to keep the gate safe.

The width and height is not needed to be changed. As conclusions, the dissipater to reduce tsunami energy is necessary in front of the gate. A horizontal red broken line in the figure indicate the.

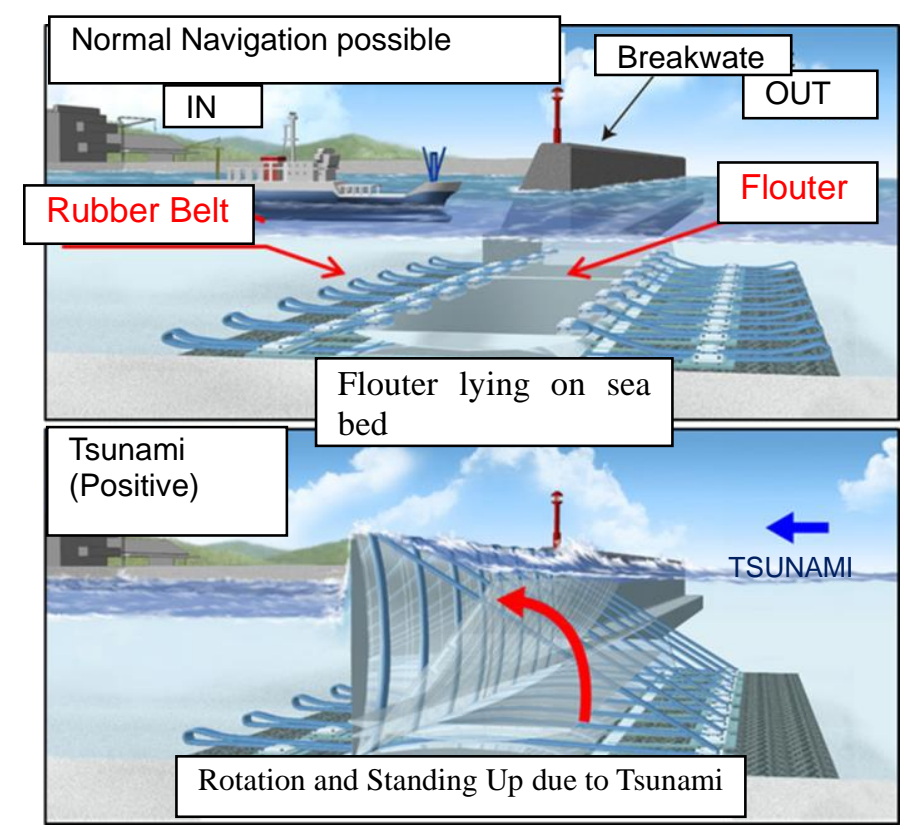

Fig.5 Mechanism of Removable Tsunami breakwater

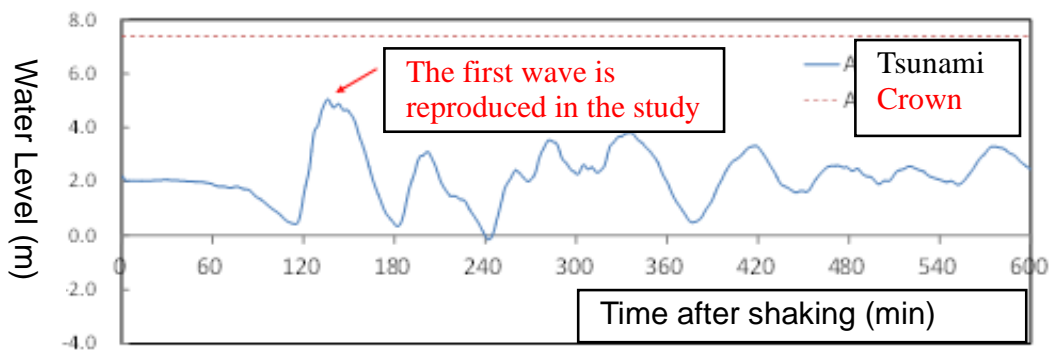

Fig.6 Tsunami profile in front of the visor gate 
crown height of the tidal gate in the target position

The experiment was done at the tsunami generation basin in Ujikawa Open Laboratory, Kyoto University. In the basin, a solitary wave is generated by a piston type wave generator. A current generator is capable to generate long periodical or uniform and combination flow in the basin as well. The length and width of the channel is 45 and $4 \mathrm{~m}$ respectively. Another end of channel is a slope of $1 / 10$. In the experiment, the hydro-plane type removable breakwater with a scale of $1 / 33$ is installed on the flat part in the channel. Figure 7 shows the cross and plane figure of the installed model inside the tsunami channel. The model unit is $43 \mathrm{~cm}$ high, $129 \mathrm{~cm}$ wide and $4.8 \mathrm{~cm}$ thick. 3 unit is employed in the experiment.

The input tsunami is divided into three category; Level 1, Level 2 and Level 3. Level 1 is the tsunami which occurs once in several ten years. Level 2 occurs once in several hundred from several thousand years. Level 3 corresponds to the mega-earthquake in which predicted all faults collapse in the South-West Japan. The tsunami height at the River gate becomes in model scale 8.8, 10.6 and 15.4cm respectively in Level 1, Level 2 and Level 3 (Figure 5). Figure 5 shows the profile of Level 2. The peak of run-up tsunami in a river is assumed to become a wave with soliton dispersion. The solitary wave is acted as a representative even in the experimental wave. As the standing wave component with long period is also included in tsunami profile, the long period variable flow is added in the specified cases. Table 1 shows the acting tsunami condition in the experiment.

The current profiles have flat peaks of $0.4 \mathrm{~m}^{3} / \mathrm{s}$ and continues for 30sec. Table 1 shows the composition of the input tsunami wave and current and their index in the paper as well. The maximum

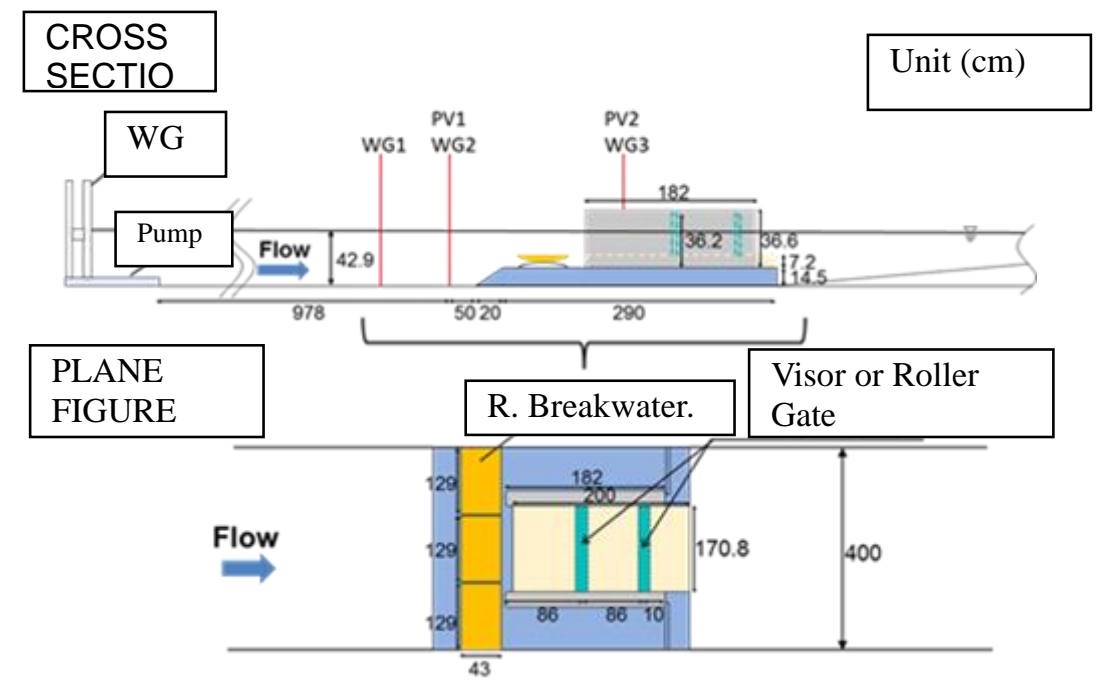

Fig.7 Experimental set-up of model breakwater and gate

\footnotetext{
* This work was financially supported by the National Nature Science Foundation of China (Grant No. 50679076) Corresponding author. E-mail: gasemi@sut.ac.ir
} 
Table 1 Experimental case

\begin{tabular}{|c|c|c|c|}
\hline No. of Case & $\begin{array}{l}\text { Input Wave } \\
\text { Height }(\mathrm{cm})\end{array}$ & Wave & $\begin{array}{c}\text { Name of } \\
\text { Case }\end{array}$ \\
\hline 1 & 8.8 & Soliton & *_L10 \\
\hline 2 & 8.8 & $\begin{array}{c}\text { Soliton } \\
+ \text { Current }(\mathrm{U})\end{array}$ & *_L101 \\
\hline 3 & 10.6 & Soliton & *_L20 \\
\hline 4 & 10.6 & $\begin{array}{c}\text { Soliton } \\
+ \text { Current(U) }\end{array}$ & *_L201 \\
\hline 5 & 15.4 & Soliton & *_L30 \\
\hline 6 & 15.4 & $\begin{array}{c}\text { Soliton } \\
+ \text { Current }(\mathrm{U})\end{array}$ & *_L301 \\
\hline
\end{tabular}

current speed in Level 2 is $0.4 \mathrm{~m}^{3} / \mathrm{s}$.

Removable breakwater is usually employed as it stands vertically on the sea bed. The final position, however, is capable to be adjusted by the length of rubber connection belts. In the experiment, the final position is varied in "Low", "Middle" and "High". Figure 8 shows the three final positions of the breakwater. The middle position is the half rising from the sea bottom and it is not perfect standing position. The duration, however, to reach is short and it is not so long to become an active energy dissipater. The distance between the breakwater and gate is changed in two patterns as shown in Figure 9. The left and right side figure correspond to the two and four times larger than the width of single unit breakwater respectively. The position of wave pressure sensors on the gate model was set every $1 \mathrm{~cm}$ on two vertical lines. In the analysis, the averaged value of all sensor's pressure is used as the representative pressure acting on the visor gate.

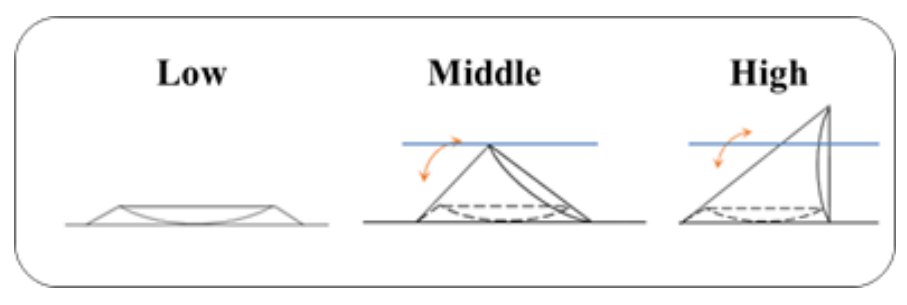

Fig.8 Position of the removable breakwater

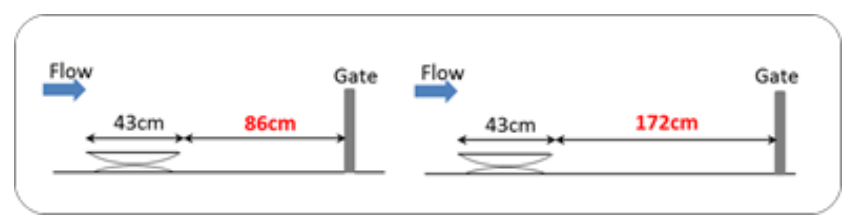

Fig. 9 Distance of gate and breakwater 


\section{Experimental Result}

The reduction rate of wave height is calculated employing as

( The maximum wave height in WG3( obtained inside the harbor)

/ ( The maximum wave height obtained outside the harbor WG1 )).

But the basement for gate is inside the harbor and the fare comparison is not capable be done. Herein, the effective height reduction rate is calculated as

$$
\text { (reduction rate in "Middle" or "High" position) / (reduction rate in "Low" ) }
$$

The effective wave pressure reduction rate is calculated as follows;

( The averaged pressure in "Middle" or "High") / ( The averaged wave pressure in "Low").

Figure 10 shows the variation of the effective reduction wave height for gate height. Figure 11 shows the variation of pressure reduction rate for the gate height. The wave height and pressure becomes reduced in case that the breakwater is adjusted in the position "Middle". The position "Middle" has a smaller inclination, so the rising motion is faster completed. Figure 12 shows the variation of height reduction for the distance between the gate and breakwater. Figure 13 shows the variation of reduction of wave pressure for the distance. In case that the distance between the breakwater and gate, the influence by the reflection wave become remarkable. The influence of the reflection wave may decrease the reduction effect of the removable breakwater for wave height and wave pressure in comparison with the wider distance. When the distance becomes $175 \mathrm{~cm}$, the averaged pressure reduction rate becomes small to 0.74 in a specified case.

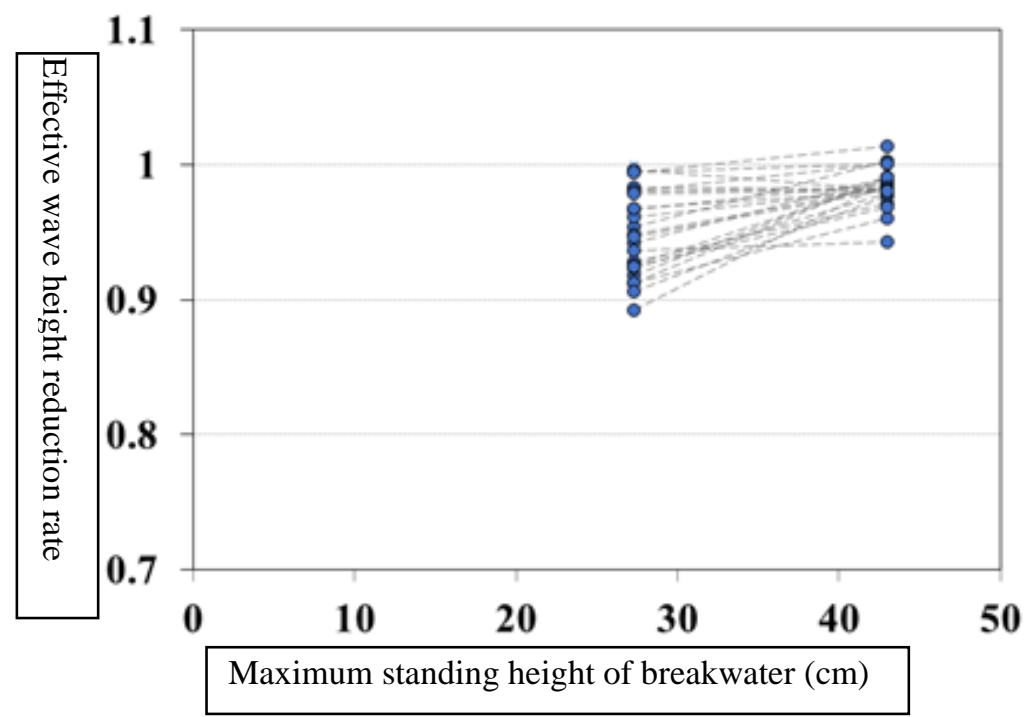

Fig.10 Effective wave height reduction rate for breakwater height

\footnotetext{
* This work was financially supported by the National Nature Science Foundation of China (Grant No. 50679076) Corresponding author. E-mail: gasemi@ sut.ac.ir
} 


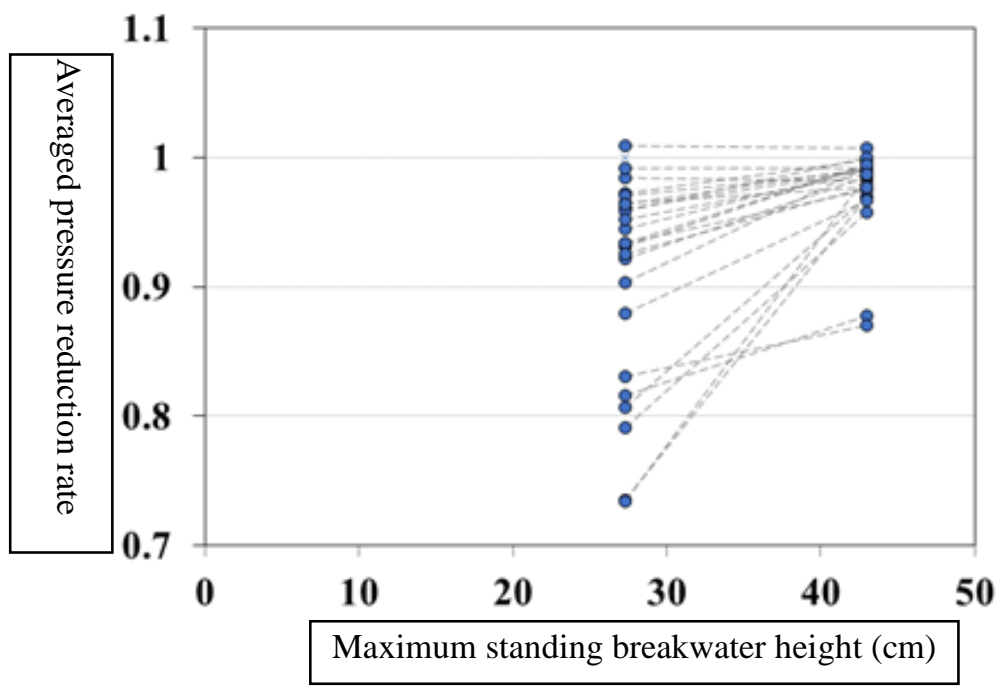

Fig.11 Averaged pressure reduction rate for maximum standing breakwater height

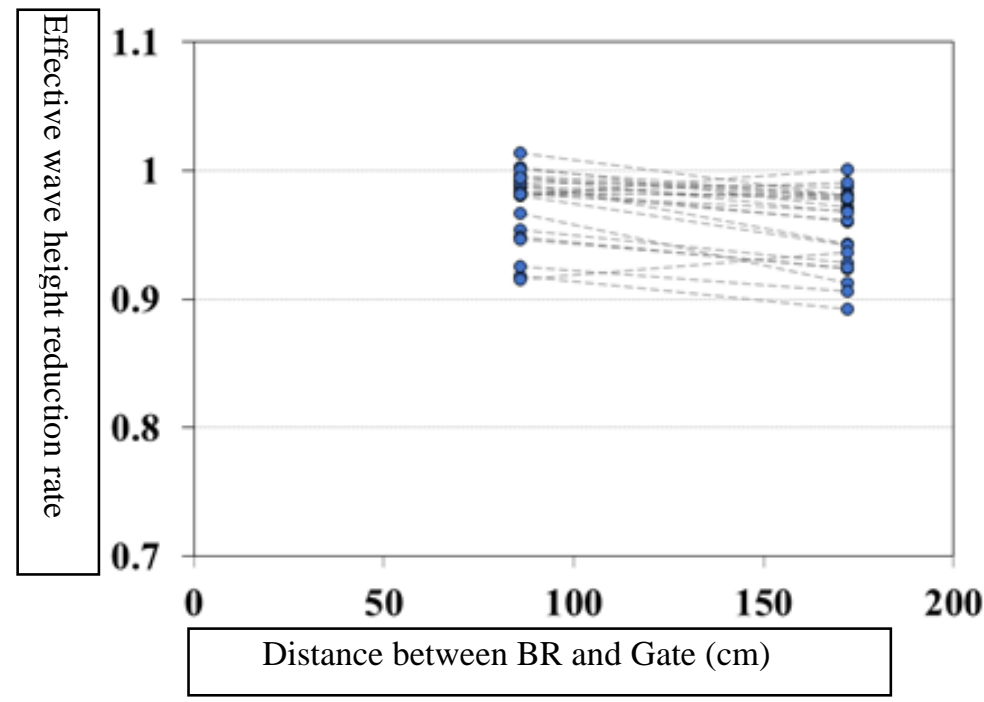

Fig.12 Effective wave height reduction rate for breakwater distance 


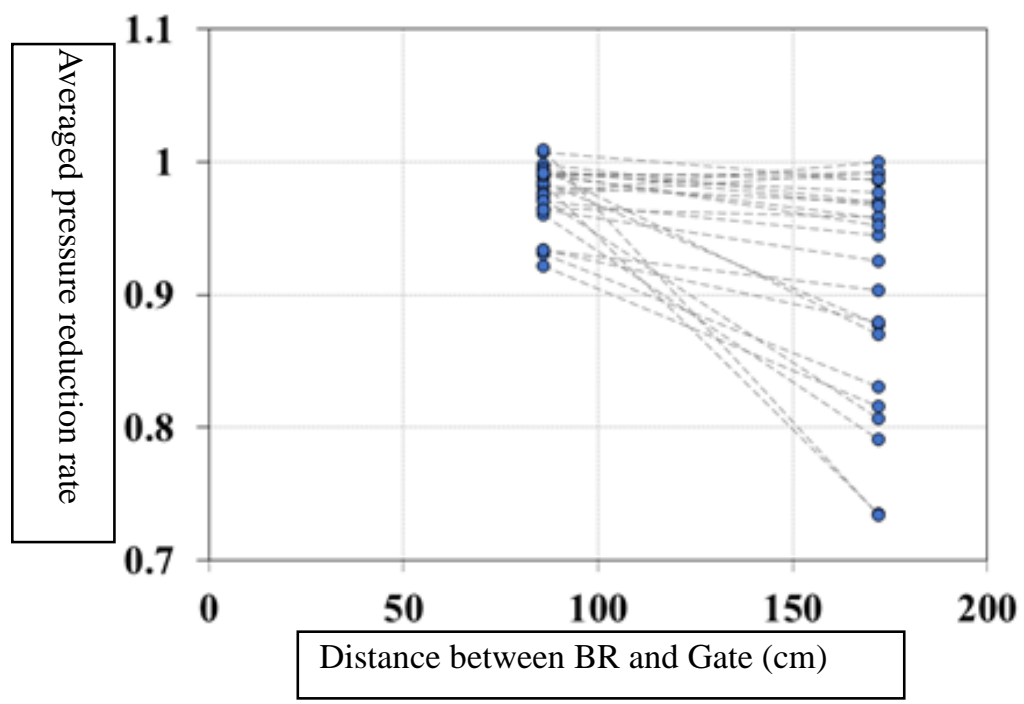

Fig.12 Effective pressure reduction rate for the distance from gate

\section{Conclusions}

The many series of fundamental model test were carried out to study on applicability of the hydroplane-type tsunami-energy dissipating gate using a tsunami basin. The following conclusions were derived.

1) The averaged wave height reduction rate becomes minimum in case of the breakwater height "Middle "

2) The averaged wave pressure reduction rate becomes minimum in case of the breakwater height "Middle"

3) The above two terms become smaller in case that the distance from the gate becomes larger.

\section{REFERENCES}

1) Azuma, R.,T. I to, H. Handa, R. Yamashiki, T. Hiraishi and T. Sugano (2014) ; Performance evaluation of Hydroplane tsunami barrier by means of small hydraulic model experiment, Journal of JSCE, Ser. B2(Coastal Engineering) Vol.70, pp.951-955.

2) Azuma, R.,T. I to, H. Handa, R., T. Hiraishi and T. Sugano (2015) ; Wave reduction effect of Hydroplane tsunami barrier in terms of hydraulic model experiments, Journal of JSCE, Ser. B2(Coastal Engineering) Vol.71, pp.1081-1086.

3) Azuma, R.,T. I to, H. Handa, R. T. Ueki and T. Hiraishi (2016) ; Full-scale model experiments on response characteristics of Hydroplane tsunami barrier, Journal of JSCE, Ser. B2(Coastal Engineering) Vol.72, pp.10991104.

\footnotetext{
* This work was financially supported by the National Nature Science Foundation of China (Grant No. 50679076)

Corresponding author. E-mail: gasemi@sut.ac.ir
} 